\title{
Author Correction: Advances in sperm analysis: techniques, discoveries and applications
}

Changsheng Dai®D, Zhuoran Zhang $\mathbb{D}^{\mathrm{D}}$, Guanqiao Shan, Lap-Tak Chu, Zongjie Huang, Sergey Moskovtsev, Clifford Librach, Keith Jarvi (iD) and Yu Sun (D)

Correction to: Nature Reviews Urology https://doi.org/10.1038/s41585-021-00472-2, published online 01 June 2021.

The original version of this article misspelled the name of Sergey Moskovtsev, who was listed as Sergey Moskovstev. This error has now been corrected in the HTML and PDF versions of the article.

https://doi.org/10.1038/s41585-021-00512-x I Published online 10 August 2021

(C) Springer Nature Limited 2021 